UVX 2012, 01001 (2013)

DOI: $10.1051 /$ uvx/201301001

(C) Owned by the authors, published by EDP Sciences, 2013

\title{
Imaging methodologies in natural sciences: The AST-RX Platform (Accès Scientifique à la Tomographie à Rayons $X$ ) of the Muséum national d'Histoire naturelle. Paris
}

\author{
M. Garcia Sanz ${ }^{1}$, F. Goussard ${ }^{1,2}$, A. Balzeau ${ }^{1,3}$ and G. Clement ${ }^{1,2}$ \\ ${ }^{1}$ UMS 2700 Outils et Méthodes de la Systématique Intégrative, département Systématique et \\ Evolution, Muséum national d'Histoire naturelle, 57 rue Cuvier, BP. 51, \\ 75231 Paris Cedex 05, France \\ 2 UMR-CNRS 7207 CR2P, Département Histoire de la Terre, Muséum national d'Histoire \\ naturelle, 57 rue Cuvier, BP. 51, 75231 Paris Cedex 05, France \\ ${ }^{3}$ UMR-CNRS 7194, Département de Préhistoire, Muséum national d'Histoire naturelle, \\ 57 rue Cuvier, BP. 51, 75231 Paris Cedex 05, France
}

\begin{abstract}
X-ray Computed Tomography (CT) scanning is a powerful imaging process for the digitization, exploration and 3D modeling of objects in the natural sciences. It allows for the observation of the internal structures of any type of sample (mineral, fossil, extant) on a sub-micron scale. The finest structures can be selected and extracted as virtual 3D models, and quantified in a repetitive way. These CT-scanned models have applications for the preventive conservation of rare and fragile specimens. The Museum national d'Histoire naturelle, Paris, France, recently acquired a high-resolution CT scan, a v|tome|x L240-180 from GE Sensing and Inspection Technologies phoenix|x-ray, with unique performance capabilities and applications for the natural science field. Indeed, the two x-ray microfocus and nanofocus sources, coupled with a large-size detector, allow for the imaging of samples with extremely variable sizes and densities. Here we present the new MNHN CT scanning Platform "AST-RX" and some results of several projects developed using it.
\end{abstract}

\section{TECHNOLOGY}

The v|tome |x L240-180 from GE Sensing and Inspection Technologies phoenix|x-ray consists of two exchangeable X-ray tubes (microfocus and nanofocus), a large movable detector, and a wide multi-axis granite-based manipulation system encompassed in a large X-ray safety cabinet, which allows the safe positioning of large rare specimens. The scanner's dimensions are $450 \times 240 \times 301 \mathrm{~cm}(\mathrm{~W} \times \mathrm{H} \times \mathrm{D})$ and it weighs about $17.700 \mathrm{Kg}$, figure 1 .

The X-ray $240 \mathrm{kV} / 320 \mathrm{~W}$ microfocus directional tube uses a $5 \mu \mathrm{A}-3000 \mu \mathrm{A}$ current range with 1 micron detail detectability, the X-ray nanofocus $180 \mathrm{kV} / 15 \mathrm{~W}$ uses a $5 \mu \mathrm{A}-800 \mu \mathrm{A}$ current range and achieves a detail detectability up to 0.5 microns. The target either consists of a thin tungsten layer (molybdenum target is also available for transmission tube) deposited on a light metal plate which also is the exit window for the $\mathrm{X}$-radiation (transmission tube) or a massive tungsten cylinder (directional tube).

The Amorphous Silicon Flat panel Detector is formed by a matrix of $2024^{2}$ pixels ( 200 microns pixel pitch) in an active area of $40 \times 40 \mathrm{~cm}$. It allows for the acquisition of several hundreds to thousands of radiographs in only a single operation cycle ( $30 \mathrm{fps}$ max. image acquisition rate). Large specimens (max. $60 \mathrm{~cm}$ length $/ 50 \mathrm{~cm}$ in diameter and $50 \mathrm{Kg}$ in weight) can be studied thanks to "multi|scan" (vertical detector and tube movements) and "Vsensor" (horizontal detector movement) modes.

This is an Open Access article distributed under the terms of the Creative Commons Attribution License 2.0, which permits unrestricted use, distribution, and reproduction in any medium, provided the original work is properly cited. 
A
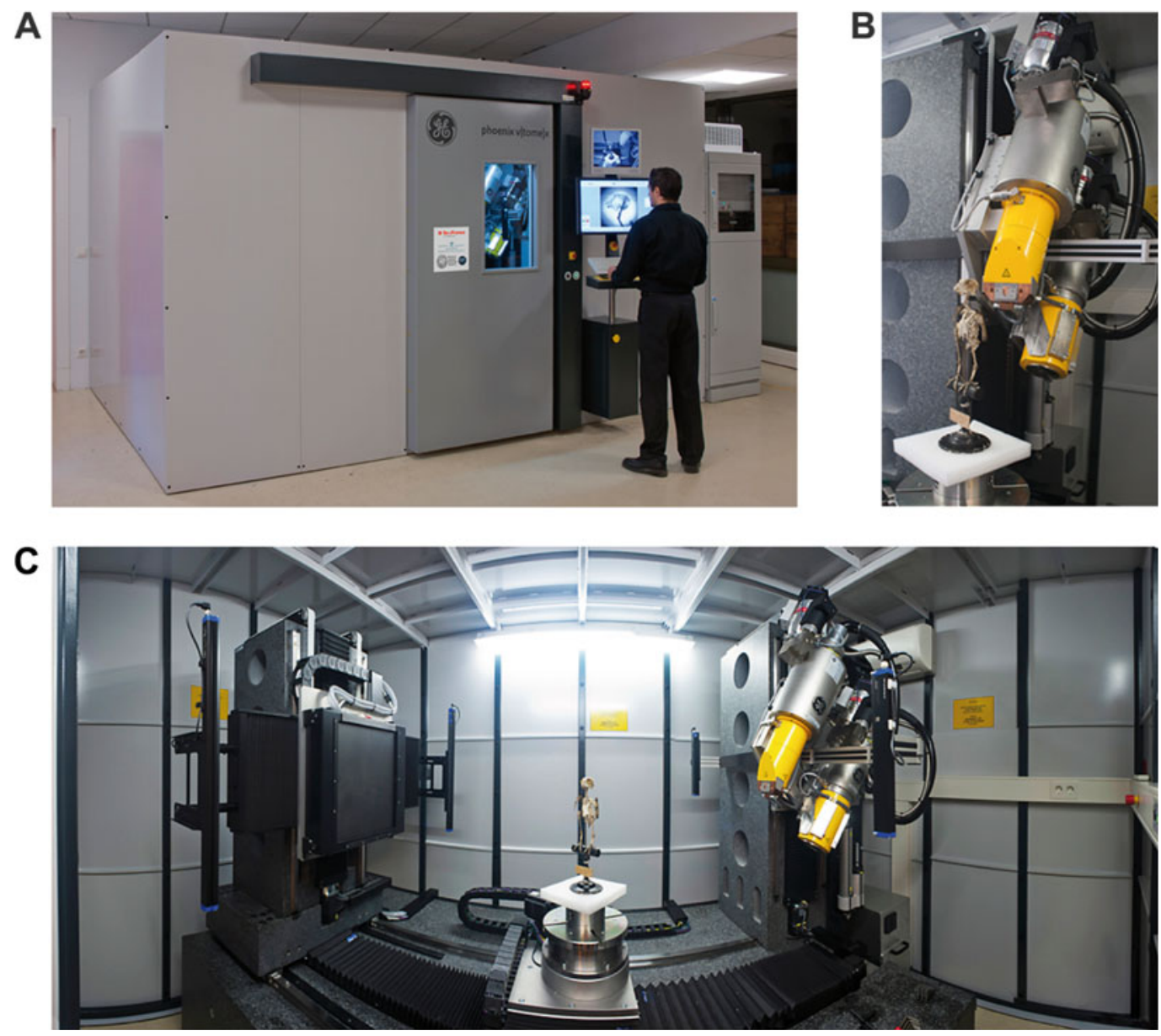

Figure 1. A, External view of the v|tome $\mid x$ L240-180 from GE Sensing and Inspection Technologies phoenix $\mid x-r a y$, MNHN, Paris. B, detail of the two X-ray sources. C, inside view of the equipment.

Low acquisition times (10 min) are possible thank to "fast|scan" mode (continuous scan). The "normal|scan" and "multi|scan" modes increase acquisition time from 10 min to a number of hours depending on the parameters selected (exposition time, number of images average, number of images skip, etc.). Reconstruction time for one scan is about $15 \mathrm{~min}$ or less.

\section{ACQUISITION, RECONSTRUCTION AND POST-TREATMENT}

Numerisation of objects in the natural sciences using CT takes place in three stages: Acquisition, Reconstruction and Post-Treatment (figure 2). The object, encompassed in a radio transparent support, is first placed on the rotatory manipulator with its largest dimension oriented vertically.

A series of two dimensional X-ray images (radiographs) are acquired while progressively rotating through a full $360^{\circ}$ rotation. Parameters such as voltage, current, and exposition time are selected according to the object's characteristics. The $2 \mathrm{D}$ projections contain information on the position and density of absorbing object features in the sample. This accumulation of data is used for the numerical reconstruction of the volumetric data, and virtual slices in any chosen orientation then are created. 


\section{UVX 2012}

A

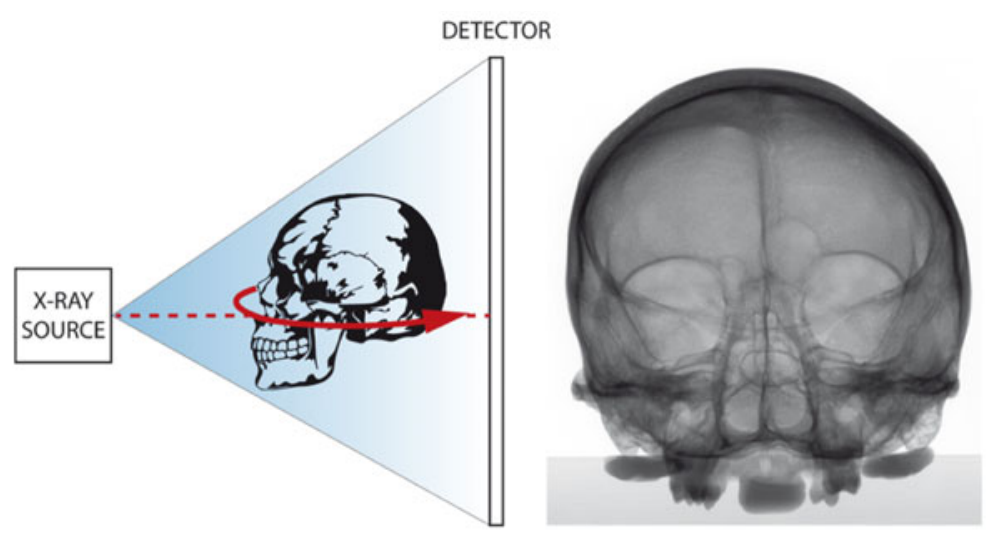

B

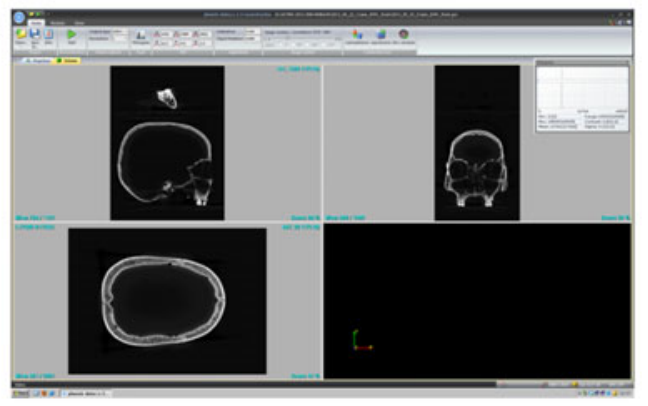

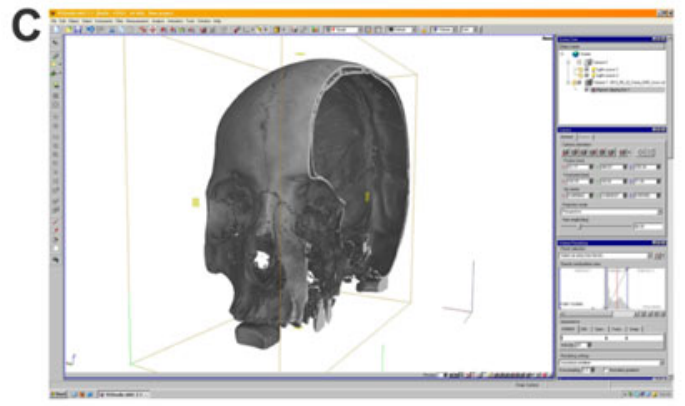

Figure 2. Process of a recent Homo sapiens skull study using CT. A, acquisition stage. B, slices reconstruction, software datos|reconstruction (GE phoenix|x-ray). C, 3D visualization, software VGStudio Max (Volume Graphics).

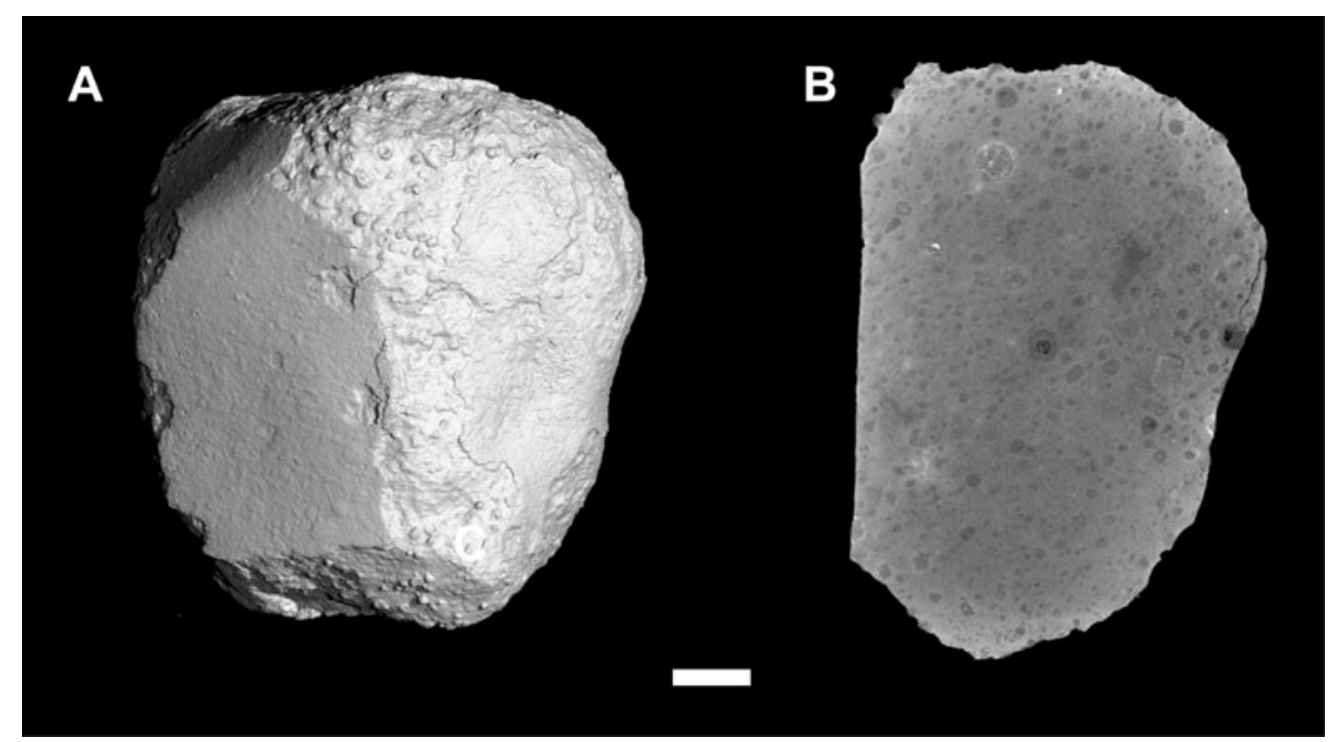

Figure 3. A, 3D view of a meteorite. B, slice view, black points show porosity regions. Size $\sim 5 \mathrm{~cm}$, scan resolution: $25 \mu \mathrm{m}$. 
Web of Conferences

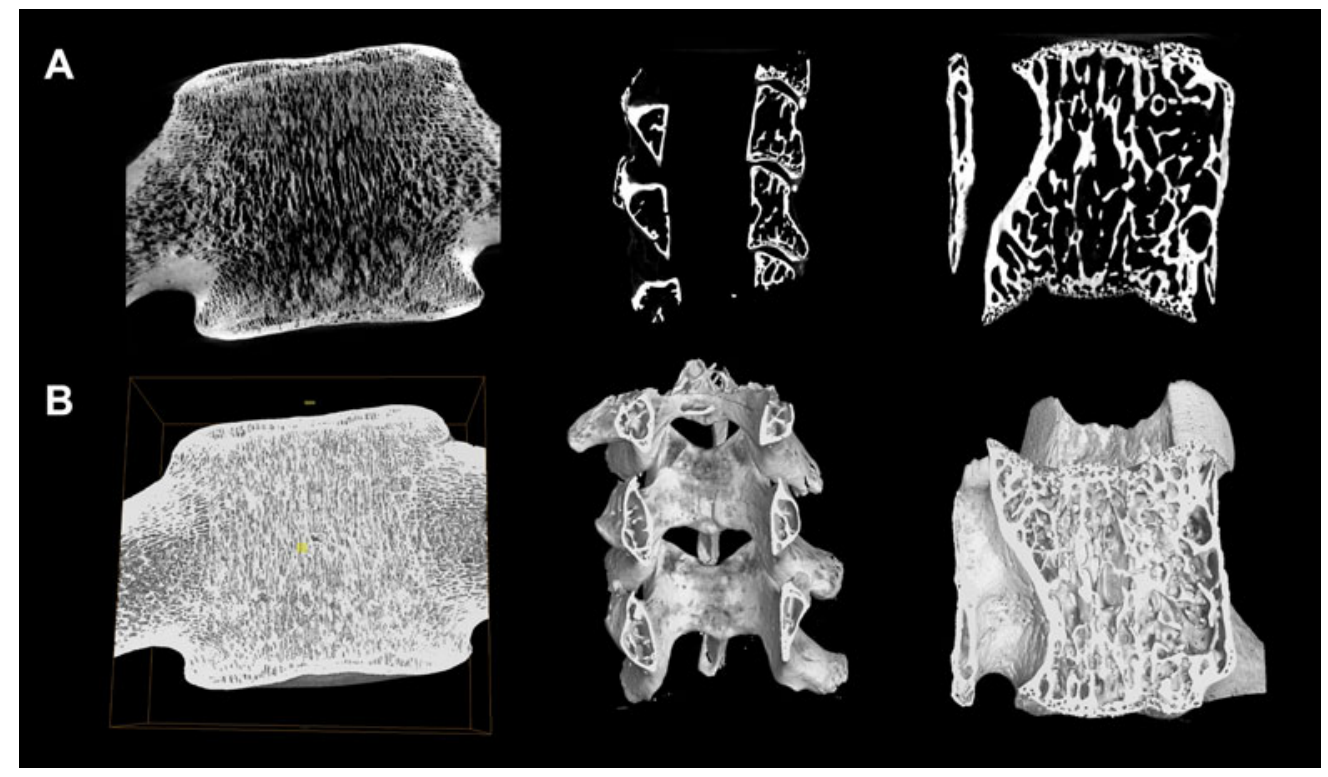

Figure 4. Longitudinal sections (A) and 3D virtual models (B) of three vertebrae. Sizes $\sim 1-20 \mathrm{~cm}$, scan resolution: $7-135 \mu \mathrm{m}$.

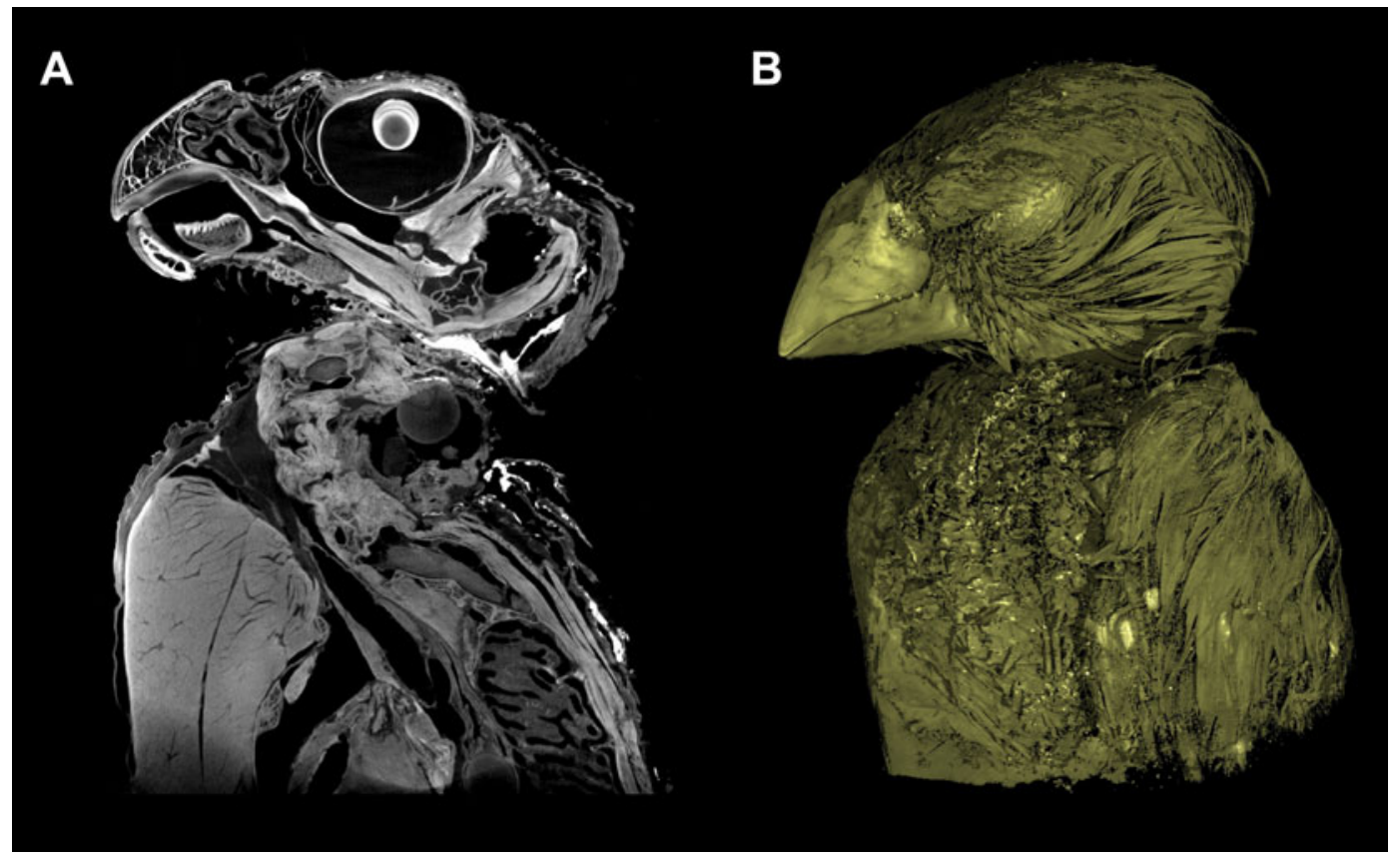

Figure 5. Longitudinal section (A) and 3D view (B) of a zebra finch pre-treated with a contrast agent. Size $\sim 11 \mathrm{~cm}$, scan resolution: $15 \mu \mathrm{m}$ (multi|scan). 


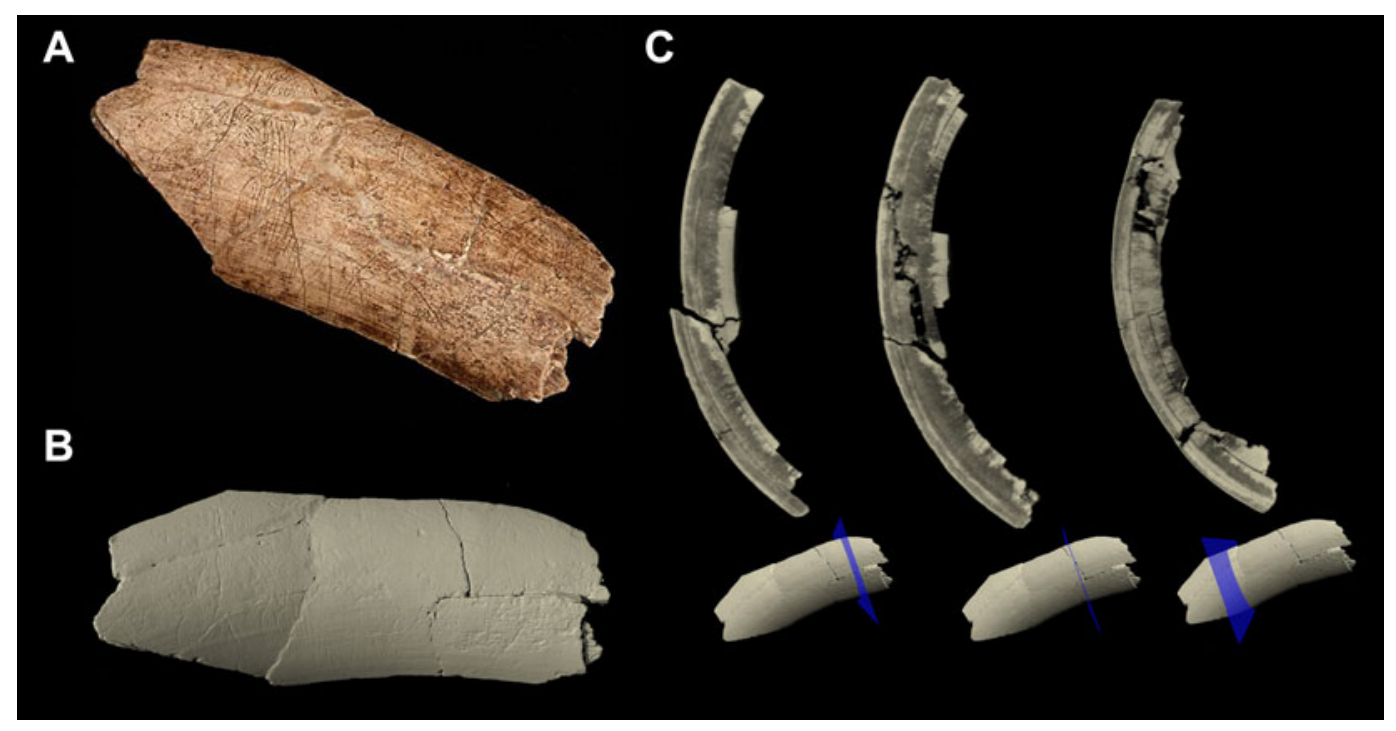

Figure 6. Madeleine's Ivory plaque, original view (A), 3D virtual model (B), transversal sections (C) showing "hidden" fractures. Size $\sim 20 \mathrm{~cm}$, scan resolution: $130 \mu \mathrm{m}$.

Several algorithms allow for the optimization of the reconstruction by correcting ring, edge or streak artifacts in the image.

Post-treatment (segmentation, quantifying, etc.) necessitates highly specialized software, for instance VGSTUDIO MAX (Volume Graphics), MIMICS (Materialise), AVIZO (Visualization Science Group) or ARTECORE (Nespos). 3D pre-rendering and rapid segmentation of reconstructed data are possible on the AST-RX Platform.

\section{RESULTS}

The main objective of the AST-RX platform is to allow for the digitization of the MNHN collections. The platform is accessible under conditions to every person wishing to digitize specimens (in particular those from the MNHN collections) for scientific research purposes, valorisation, the conservation of natural science collections, or knowledge dissemination (information about access and online formularies: http://formulaires.mnhn.fr/fr/ast-rx/numerisation).

The results obtained with the v|tome|x L240-180 demonstrate the potential of the AST-RX Platform in terms of research, collections valuation and preventive conservation. The technical capacities of this equipment make possible the study of the finest internal structures of specimens with variable dimensions (ranging from millimetres to several decimetres) and of various densities (organ, insect, fossil, mineral, etc.), thus allowing for a wide variety of applications. Some of them are illustrated below.

\subsection{Study of meteorites}

Magnetism measurements are taken in both before and after the acquisition, as the main goal is to determine the influence of CT scanning on the sample's magnetism. CT scans show clear information about density and porosity and high precision volume calculations can be implemented (figure 3 ). 


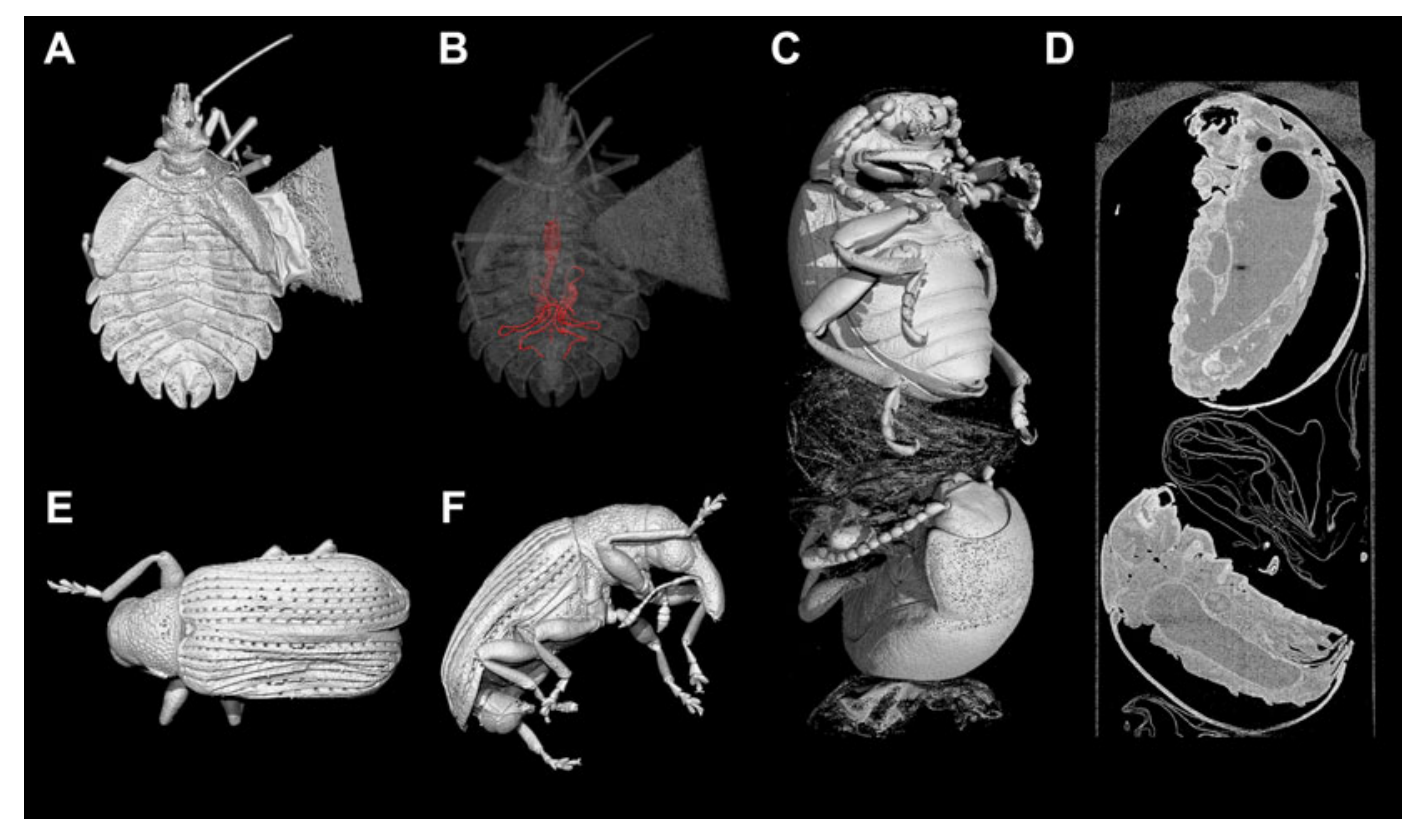

Figure 7. A. Actual tingid larva in $3 \mathrm{D}$ view, Size $\sim 4 \mathrm{~mm}$, scan resolution: $3 \mu \mathrm{m}$, B. Actual tingid larva, digestive apparatus and parasites, C. Actual Timarcha sp. 3D view, Size $\sim 8 \mathrm{~mm}$, scan resolution: $9.7 \mu \mathrm{m}$, C. Actual Timarcha sp. longitudinal slice, E, F. Fossil coleopteran insect virtually extracted from amber, Size $\sim 3 \mathrm{~mm}$, scan resolution: $2.5 \mu \mathrm{m}$.

\subsection{Study of the internal structure of mammal's vertebras}

A large series of vertebrae from different-sized species have been studied. The results obtained using CT scans allow for the comparison of internal architectures and parameters such as porosity, bone compactness, etc. (figure 4). Finite elements studies of vertebrae 3D virtual models can be carried out to analyse mechanical stress.

\subsection{Biomechanical study of a zebra finch}

High resolution CT data of zebra finch internal structures (figure 5) have been combined with cineradiography models which allow for the study of both the dynamics and kinematics of take-off and landing in birds.

\subsection{Study of archaeological objects}

CT scan can be used for preventive conservation and for the restoration of archaeological objects. Here La Madeleine's Ivory plate has been studied. Results show new "hidden” fractures (figure 6).

\subsection{Study of insects (actual and fossilized within amber)}

CT scans show great potential for studying both actual and fossil insects. 3D models and slices of actual insects allow one to see the internal structures in a non-destructive way and can be used for "virtual" dissections (figure 7A, 7B, 7C, 7D). Specimens preserved in amber for millions of years can be virtually "extracted" (figure 7E, 7F). 
A
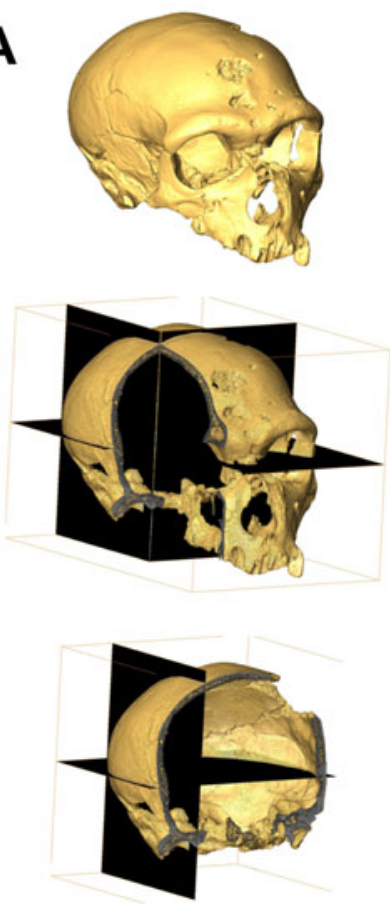
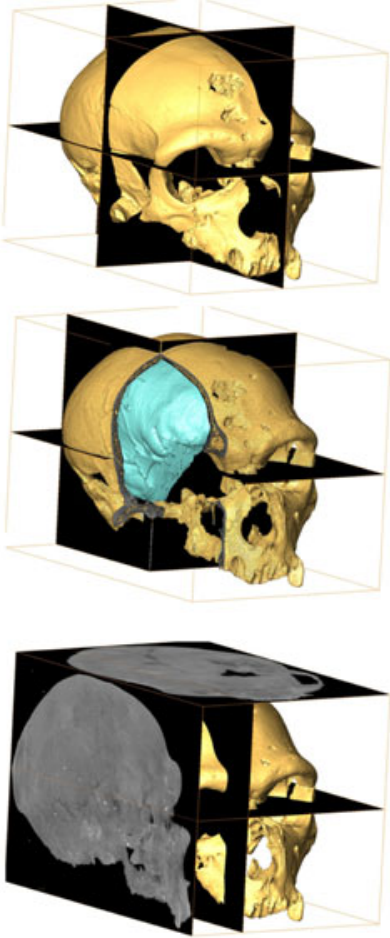

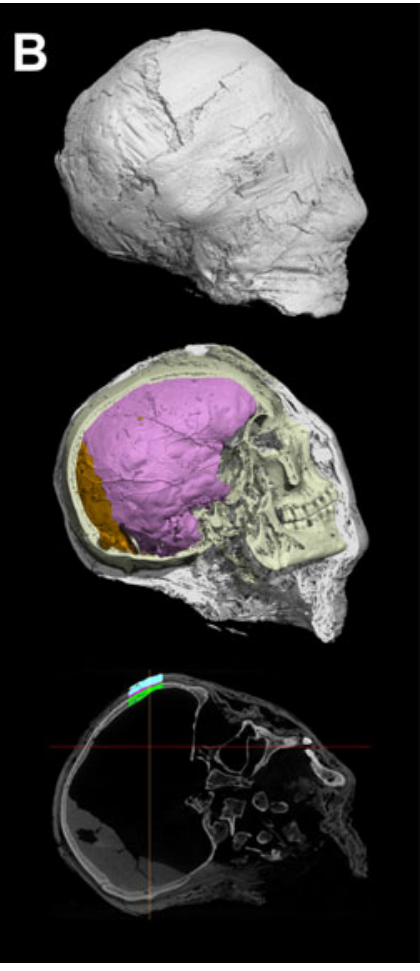

Figure 8. A. Virtual images of the Neanderthal skull from "La Chapelle-aux-Saints"; slices and 3D models of cranium (in yellow) and endocranium (in blue), Size $\sim 16 \mathrm{~cm}$, scan resolution: $100 \mu \mathrm{m}$. B. 3D virtual model and parasagittal slice view of a mummified Egyptian head, Size $\sim 20 \mathrm{~cm}$, scan resolution: $136 \mu \mathrm{m}$.

\subsection{Study of paleontological and anthropological collections}

Results obtained from specimens in MNHN paleontological and anthropological collections demonstrate the great capability of CT scans for research and collections valorisation (figure 8).

\section{Acknowledgements}

We thank B. de Buffrenil (MNHN), P. Provini (MNHN), P. Mennecier (MNHN), M. Baylac (MNHN) for allowing the dissemination of the images presented here and A. McGrosky for proofreading.

\section{References}

[1] G. Clément, D. Geffard-Kuriyama, 3D \& imgaerie en sciences paléontologiques et paléoanthropologiques, $\mathrm{N}^{\circ}$ spécial de Comptes-rendus Palevol, vol. 9, 6-7, 2012, pp 255-470

[2] G.W. Weber, F.L. Bookstein, Virtual Anthropology: A guide to a new interdisciplinary field, Springer, 2011 